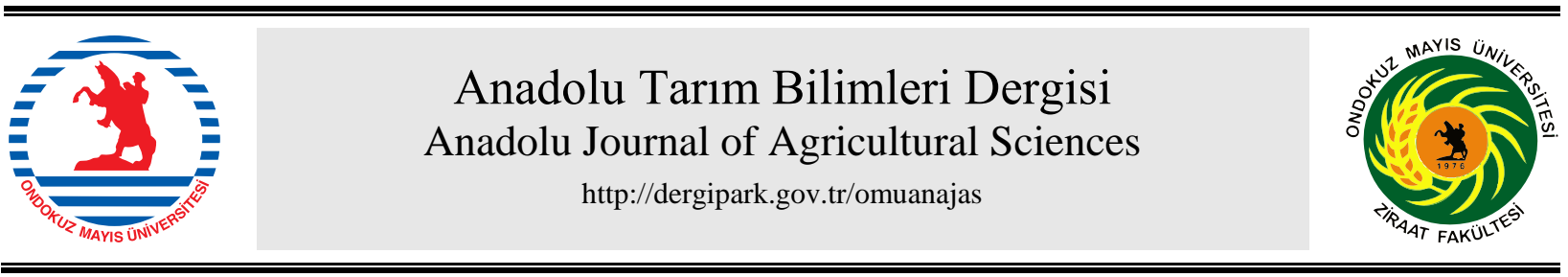

Araştırma/Research

Anadolu Tarım Bilim. Derg./Anadolu J Agr Sci, 34 (2019) ISSN: 1308-8750 (Print) 1308-8769 (Online) doi: 10.7161/omuanajas.403794

\title{
Kireçli ana materyal üzerinde oluşan topraklarda fosfor fraksiyonları ile bazı toprak özellikleri arasındaki ilişkiler
}

\author{
Hasan Hadi Mahdi Mahdi ${ }^{\mathrm{a}}$, Veli Uygur ${ }^{\mathrm{b} *}$, Burak Durgun ${ }^{\mathrm{b}}$ \\ ${ }^{a}$ Bilim ve Teknoloji Bakanlığl, Tarımsal Araştırmalar Müdürlüğü, Toprak ve Su Araştırma Bölümü, Bağdat/Irak \\ ${ }^{b}$ Isparta Uygulamalı Bilimler Üniversitesi, Tarım Bilimleri ve Teknolojileri Fakültesi, Toprak ve Bitki Besleme Bölümü,32260 Isparta/Türkiye \\ "Sorumlu yazar/corresponding author: veliuygur@sdu.edu.tr
}

Geliş/Received 09/03/2018～Kabul/Accepted 18/11/2018

\begin{abstract}
ÖZET
Fosfor (P), birçok fizyolojik ve biyokimyasal süreçte önemli bir element olduğu için bilinen tüm canlılar için mutlak gereklidir. Toprak oluşum süreçlerine ve arazi kullanımına bağlı olarak ortaya çıkan toprak özellikleri topraklarda fosforunun yarayışlılığı ve jeokimyasal fraksiyonlarında değişikliklere neden olmaktadır. Bu çalışmada Atabey Ovası'ndan toplam 71 adet yüzey toprak örneği $(0-20 \mathrm{~cm})$ alınmıştır. Topraklarda kademeli fosfor fraksiyonlaması yapılmıştır. Bu fraksiyonlar; sodyum bikarbonat $\left[\mathrm{NaHCO}_{3}-\mathrm{P}\right.$ (organik Po, inorganik Pi ve total $\mathrm{Pt}$ )], sodyum hidroksit $[\mathrm{NaOH}-\mathrm{P}$ (organik Po, inorganik Pi ve total Pt)], sitrat bikarbonat dithionit (CBD-P), hidroklorik asit ile ekstrakte edilebilen (Ca-P) ve bakiye (Res-P) fosfor şeklindedir. Fosfor fraksiyonlarının toprak özellikleri ile olan ilişkileri tanımlayıcı istatistik analizleri, Pearson korelasyon analizi ve kemometrik analizlerle ortaya konulmaya çalışmıştır. Ova topraklarında fraksiyonların ortalama dağılım sırası büyükten küçüğe doğru Ca-P $(\%$ 50.36) > Res-P (\% 19.94) > CBD-P (\% 12.17) > NaOH-Pt (\% 6.94) > NaOH-Pi (\% 6.24) > $\mathrm{NaHCO}_{3}-\mathrm{Pt}\left(\%\right.$ 1.82) $>\mathrm{NaHCO}_{3}-\mathrm{Pi}\left(\%\right.$ 1.57) $>\mathrm{NaOH}-\mathrm{Po}\left(\%\right.$ 0.71) $>\mathrm{NaHCO}_{3}-\mathrm{Po}(\% 0.25)$ şeklinde izlenmiştir. $\mathrm{Bu}$ fraksiyonların oransal dağılımının arazi kullanım şekline bağlı gübreleme miktarına göre değiştiği belirlenmiştir.
\end{abstract}

The relations between phosphorus fractions and some soil properties in soils forming on calcareous parent material

\begin{abstract}
Phosphorus (P) is essential to all known life forms because it is a key element in many physiological and biochemical processes. Soil properties due to soil formation processes and land use have impacts on the availability of phosphorus in soils and on the change in geochemical fractions. Thus, total of 71 surface soil samples $(0-20 \mathrm{~cm})$ were taken from the Atabey Plain. The sequential extraction procedure was executed in the samples. The determined fractions were: sodium bicarbonate $\left[\mathrm{NaHCO}_{3}-\mathrm{P}\right.$ (organic $\mathrm{Po}$, inorganic $\mathrm{Pi}$ and Total $\mathrm{Pt}$ )], sodium hydroxide [NaOH-P (organic Po, inorganic $\mathrm{Pi}$ and Total $\mathrm{Pt}$ )], citrate bicarbonate dithionite (CBD-P), hydrochloric acid (Ca-P), and residual (Res-P) phosphorus. Relations of phosphorus fractions with soil properties were revealed by descriptive statistics, Pearson correlation analysis and chemometric analysis. The average distribution of fractions in the plain soils in descending order were: Ca-P (\% 50.36) > Res-P (\% 19.94) > CBD-P (\% 12.17) > NaOH-Pi $(\% 6.24)>$ $\mathrm{NaHCO}_{3}-\mathrm{Pi}\left(\%\right.$ 1.57) $>\mathrm{NaOH}-\mathrm{Po}\left(\%\right.$ 0.71) $>\mathrm{NaHCO}_{3}-\mathrm{Po}(\%$ 0.25). It was determined that the fractal distribution of these fractions changed according to the land use pattern-dependent on fertilizer usage.
\end{abstract}

Anahtar Sözcükler: Atabey Ovas1 Fosfor (P) Kemometrik analizler Siralı ekstraksiyon

\section{Giriş}

Topraklarda fosfor; organik fosfor ve inorganik fosfor olmak üzere iki ana grup altında toplanabilir.
Değişen toprak koşulları, gübreleme programı ve bitki örtüsü bu fraksiyonların kendi içerisinde ve farklı fraksiyonlar arasında fosfor geçişlerini etkilemektedir (Uygur ve ark., 2017). Çeltik topraklarında başat 
inorganik fosfor fraksiyonu olarak belirlenen Ca-P fraksiyonunun indirgen toprakların $\mathrm{pH}$ değişimlerine bağlı olarak ve toprakların $\mathrm{CaCO}_{3}$ içeriğindeki azalmaya bağlı olarak sürekli azaldığı saptanmıştır. Karbonatlar tarafindan tutulmuş fosfor (Ca-P) fraksiyonunu miktarca, CBD-P (Demir oksitler ile hidroksi oksitler içerisinde oklüde olmuş fosfor) ve Al-P + Fe-P (Alüminyum ve demire bağlı oklüde olmamıș fosfor) ve bakiye-P fraksiyonları izlemiştir (Kacar ve Katkat, 2009). Fosfat iyonları ayrıca ortamdaki $\mathrm{Ca}, \mathrm{Mg}$, Al ve Fe gibi elementlerle birleşerek çökelti oluşturmak suretiyle de yarayışsız hale geçtiği bilinmektedir (Kacar ve Katkat, 2009; Karaman, 2012).

Asit topraklarda Al-P ve Fe-P'deki artış, esasen indirgeyici çözünebilir ve oklüde-P formlarının baskınlığ 1 nedeniyle, Ca-P'deki azalmadan daha az gerçekleştiği tespit edilmiştir (Tandon, 1987). Kireçli topraklar üzerinde yapılan birçok çalışma, $\mathrm{P}$ davranışının esas olarak az miktarda bulunan demir veya alüminyum oksitlerin varlığı ile kontrol edildiğini göstermiştir (Solis ve Torrent, 1989). Buna karş1l1k Korkmaz (2005), kireçli topraklardaki toplam fosforun sirasiyla $\mathrm{Ca}-\mathrm{P}>\mathrm{CDB}-\mathrm{P}>\mathrm{CB}-\mathrm{P}>\mathrm{Al}-\mathrm{P}+\mathrm{Fe}-\mathrm{P}$ fraksiyonlarında dağılım gösterdiğini bildirmiştir. Saltalı ve ark. (2007) çayır-mera topraklarının tarıma açılmasıyla organik ve inorganik $\mathrm{P}$ fraksiyonlarının önemli ölçüde azaldığını tespit etmiştir. Halajnia ve ark. (2009) inorganik gübreleme yapılmış kireçli topraklarda Olsen-P ile $\mathrm{NH}_{4}$-asetatta çözünen $\mathrm{Al}$ ve aktif kireç arasında pozitif bir ilişki belirlemiştir. Aynı çalışmada ilk 30 günde CBD-P'nin miktarındaki artış, Fe oksitlerin topraklarda P sorpsiyonunda önemini ortaya koymuştur. Fosfor fraksiyonlarının oransal dağılımı HCl-P > OAc-P $>$ Organic-P > CBD-P > Olsen-P > NaCl-NaOH-P sırasını izlemiştir.

Dieter ve ark. (2010) İnceptisol, Alfisol ve Oxisol ordolarındaki topraklarda arazinin jeolojisi, topoğrafyası ve bitki örtüsünün fonksiyonu olarak hareketli $\mathrm{P}$ fraksiyonundaki inorganik ve organik fosforun oransal miktarının \% 4.7-11.4 arasında değişim gösterdiğini bildirmiştir. Diğer taraftan Achat ve ark. (2016), asidik ve asidik olmayan topraklarda fosfat iyonlarının dinamiklerinin kontrolünde alüminyum ve demir oksitlerin ve organik karbonun baskın rolünü ortaya koymuştur. Gübrelemenin fosfor fraksiyonlarına etkisinin anlaşılması açısından Alovisi ve ark. (2016) yaptıkları çalışma, inorganik $P$ gübrelemesinin orta labil ve labil $P$ fraksiyonları üzerine etkisinin yüksek olduğunu göstermiştir. Organik $\mathrm{P}$ fraksiyonlardan $\mathrm{NaHCO}_{3}$-Po fraksiyonu bitki beslemesine katkıda bulunan tek fraksiyon olduğu gözlenmiştir. Bu duruma paralel olarak Maranguit ve ark. (2017), yarayışlı P fraksiyonları $\left(\mathrm{H}_{2} \mathrm{O}-\mathrm{Pi}, \mathrm{NaHCO}_{3}-\mathrm{Pi}\right.$ ve $\left.\mathrm{Po}\right)$ ve toplam organik $\mathrm{P}$ miktarı ile karbon içeriği arasında kuvvetli pozitif korelasyon gözlemişlerdir.

Mevcut literatürler 1şığında bu çalışmada Atabey Ovası topraklarında fosfor fraksiyonları üzerine toprak özellikleri tanımlayıcı istatistikler, Pearson korelasyon ve temel bileşen analizleri kullanılarak ortaya konulmaya çalışılmıştır.

\section{Materyal ve Yöntem}

\subsection{Toprak örneklerinin alınması}

Atabey Ovası'nda yer alan 20 toprak serisinden her bir seriden en az üç alt örnek olmak üzere toplamda 71 adet kompozit yüzey toprağ örneği $(0-20 \mathrm{~cm})$ alınmıştır (Durgun, 2016). Topraklar, hava kuru durumuna geldikten sonra $2 \mathrm{~mm}$ 'den elenmiş ve aşağıda belirtilen tanımlayıcı analizler ve $\mathrm{P}$ fraksiyonlaması yapılmıştır.

\subsection{Toprakların tanımlayıcı özellikleri}

Toprak örneklerinde, amonyum asetatla ekstrakte edilebilen $\mathrm{Na}, \mathrm{K}, \mathrm{Ca}$ ve $\mathrm{Mg}$ (Rhoades, 1982), organik madde (OM) modifiye edilmiş Walkley-Black metodu ile potasyum dikromat $\left(\mathrm{K}_{2} \mathrm{Cr}_{2} \mathrm{O}_{7}\right)$ ile yaş yakarak (Nelson ve Sommers, 1982), toprak reaksiyonu ve elektriksel iletkenliğini sirasıyla $\mathrm{pH}$-metre ve Wheatstone köprüsü prensibiyle saturasyon çamurunda, yarayışlı fosfor Olsen metodu ile, katyon değişim kapasitesi (KDK) sodyum asetat (1 M, pH 8.2) yöntemi ile (Rhoades, 1982), tekstür Bouyoucos hidrometresi ile belirlenmiş̧ir (Gee ve Bauder, 1986). Toprakların kireç eşdeğerleri Scheibler kalsimetresinde manometrik metot ile belirlenmiştir (Nelson, 1982). Topraklarda aktif kireç Drouineau (1942) tarafindan bildirildiği şekilde gerçekleştirilmiştir. Toprak örneklerinde belirlenmiş olan parametrelere ait tanımlayıcı istatistikler Çizelge 1 'de verilmiştir.

\subsection{Fosfor fraksiyonlarının belirlenmesi}

Topraklar, Hedley ve ark. (1982) ve Kuo (1996) kademeli ekstraksiyonlarının kombinasyonundan oluşan bir sıralı ekstraksiyon işlemine tabi tutulmuştur. Reaktifler ve operasyonel olarak tanımlanan kimyasal fraksiyonlar aşağıdaki gibidir:

Fraksiyon I $\left(\mathrm{NaHCO}_{3}-\mathrm{P}\right)$ : Bitkiye yarayışlılığı en yüksek olan detayı Olsen ve ark. (1954) tarafindan bildirildiği şekilde $\mathrm{pH}$ 's1 8.5 'e ayarlanmış 0.5 M'lık $\mathrm{NaHCO}_{3}$ çözeltisiyle 1:20 oranında yapılan ekstraksiyondur. $\mathrm{Bu}$ fraksiyon ikiye ayrılmıştır: I) molibdat ile reaksiyona girebilen inorganik $\left(\mathrm{NaHCO}_{3}{ }^{-}\right.$ Pi) ve II) konsantre $\mathrm{HNO}_{3}$ ile yakma sonucunda elde edilen toplam P'den inorganik P'nin çıkartılması ile elde edilen organik $\mathrm{P}\left(\mathrm{NaHCO}_{3}-\mathrm{Po}\right)$. Her iki fraksiyon da askorbik asit yöntemi ile renklendirildikten sonra spektrofotometrede (T 80 UV / VIS spektrofotometre) kolorimetrik olarak tayin edilmiştir (Murphy ve Riley, 1962).

Fraksiyon II. sodyum hidroksit (NaOH-P): Bir önceki aşamadan kalan toprak örnekleri $0.1 \mathrm{~N} \mathrm{NaOH}+$ $1 \mathrm{M} \mathrm{NaCl}$ çözeltisinin $50 \mathrm{ml}$ 'si ile 17 saat çalkalanmış ve daha sonra iki kez $25 \mathrm{Ml}$ 'lik $1 \mathrm{M} \mathrm{NaCl}$ ile yıkanmış ve tüm çözeltiler bir kapta toplanmıştır. Bu fraksiyon da 
Çizelge 1. Araştırma topraklarının rutin özelliklerine ait tanımlayıcı istatistikleri (N:71)

\begin{tabular}{|c|c|c|c|c|c|c|c|c|c|}
\hline Toprak & Min & Maks. & Ort. & Std. & Çarpıklık & Basıklık & Medyan & Mod & Varyans \\
\hline $\mathrm{pH}$ & 6.78 & 8.03 & 7.69 & 0.29 & -1.56 & 1.69 & 7.79 & 7.84 & 0.08 \\
\hline $\mathrm{EC}\left(\mu \mathrm{S} \mathrm{cm}^{-1}\right)$ & 105.2 & 762 & 294.6 & 120.2 & 1.03 & 2.06 & 276 & 210 & 14450 \\
\hline $\mathrm{OM}(\%)$ & 0.51 & 6.94 & 2.07 & 0.97 & 2.22 & 8.63 & 1.99 & 2.04 & 0.95 \\
\hline Kireç (\%) & 0.66 & 41.53 & 11.13 & 10.73 & 1.18 & 0.56 & 7.82 & 0.93 & 115.1 \\
\hline Aktif kireç (\%) & 0.50 & 2.83 & 1.20 & 0.56 & 0.64 & -0.14 & 1.18 & 0.57 & 0.31 \\
\hline $\operatorname{Kum}\left(\mathrm{g} \mathrm{kg}^{-1}\right)$ & 5.70 & 695 & 384.8 & 163.3 & -0.18 & -0.43 & 379.3 & 5.70 & 26695 \\
\hline Silt $\left(\mathrm{g} \mathrm{kg}^{-1}\right)$ & 118.0 & 667 & 247.4 & 95.86 & 1.45 & 3.93 & 225 & 167 & 9188 \\
\hline Kil $\left(\mathrm{g} \mathrm{kg}^{-1}\right)$ & 146.9 & 7034 & 367 & 125.3 & 0.58 & 0.16 & 353 & 146 & 15708 \\
\hline $\mathrm{KDK}\left(\mathrm{cmol} \mathrm{kg}^{-1}\right)$ & 11.20 & 62.9 & 33.68 & 10.51 & 0.57 & 0.34 & 32.80 & 27.5 & 110.4 \\
\hline $\mathrm{Ca}\left(\mathrm{cmol} \mathrm{kg}^{-1}\right)$ & 6.90 & 42 & 25.32 & 8.04 & -0.39 & -0.16 & 27 & 28.10 & 64.65 \\
\hline $\mathrm{Mg}\left(\mathrm{cmol} \mathrm{kg}^{-1}\right)$ & 1.20 & 15.8 & 5.49 & 3.10 & 1.14 & 1.11 & 4.92 & 1.41 & 9.63 \\
\hline $\left.\mathrm{K}(\mathrm{cmol} \mathrm{kg})^{-1}\right)$ & 0.41 & 3.60 & 1.59 & 0.80 & 0.86 & -0.09 & 1.35 & 0.76 & 0.64 \\
\hline $\mathrm{Na}\left(\mathrm{cmol} \mathrm{kg}^{-1}\right)$ & 0.05 & 2.15 & 0.61 & 0.27 & 2.32 & 16.15 & 0.61 & 0.61 & 0.07 \\
\hline $\mathrm{P}\left(\mathrm{mg} \mathrm{kg}^{-1}\right)$ & 3.91 & 96.7 & 18.6 & 19.36 & 2.81 & 7.95 & 13.0 & 4.48 & 374.7 \\
\hline
\end{tabular}

önceki fraksiyonda olduğu gibi iki alt fraksiyona (NaOH-Pi ve NaOH-Po) ayrılmıştır.

Fraksiyon III (CBD-P): Kuo (1996) tarafindan tarif edilen sitrat-bikarbonat-ditiyonit ekstraksiyon yöntemi ile ayrılmıştır. Bu fraksiyon, çoğunlukla serbest demir oksitlere bağlı orta derecede yarayışlı P'yi içermektedir. Renklendirme çözeltisinden renk oluşumunu iyileştirmek için $1.5 \mathrm{~mL} / 25 \mathrm{~mL} \% 5$ amonyum molibdat çözeltisi eklenmiştir (Weaver, 1974).

Fraksiyon IV (Ca- P): Örneklerdeki bakiye $\mathrm{Na}_{2} \mathrm{~S}_{2} \mathrm{O}_{4}$ oksidasyonu sağlandıktan sonra toprak örneği üzerine $50 \mathrm{~mL} 0.5 \mathrm{M} \mathrm{HCl}$ ilave edilip ve 1 saat çalkalanarak santrifüjlenmiş ve sıvı ayrılmıştır. Santrifüjlemeden sonra ekstrakt $100 \mathrm{~mL}$ 'lik ölçü balonuna konularak 25 $\mathrm{mL}$ doymuş $\mathrm{NaCl}$ çözeltisiyle 2 defa daha yıkanmış ve hacim doymuş $\mathrm{NaCl}$ ile $100 \mathrm{~mL}$ 'ye tamamlanmıştır.

Fraksiyon V (Bakiye-P): Bu fraksiyon; dirençli, bitkiye yarayışlılığı çok düşük olan, çoğunlukla primer minerallerin yapısında ve/veya çözünmemiş organik maddenin yapisında bulunan $\mathrm{P}$ fraksiyonlarını içermektedir. Dirençli fraksiyon yaş yakma $\left(\mathrm{HNO}_{3}: \mathrm{HCl}\right.$, $3: 1, \mathrm{~V} / \mathrm{V}$ ) yöntemiyle çözülmüss ve fosfor miktarı Murphy ve Riley (1962) metodu $880 \mathrm{~nm}$ dalga boyunda kolorimetrik olarak tespit edilmiştir.

\section{4. İstatistiksel analizler}

Toprakların fiziko-kimyasal özelliklerine ve fosfor fraksiyonlarına (konsantrasyon ve oransal değerler) SPSS 17.0 paket programında tanımlayıcı istatistik analizleri uygulanmıştır. Yapılan temel tanımlayıcı istatistikler sonucunda normal dağılım göstermeyen yani çarpıklık değeri $\geq 2 \times$ çarpılığın standart sapması olan özelliklerde log transformasyonu yapılarak veri setinin normal dağılıma sahip olması ya da normal dağılıma yaklaştırılması sağlanmıştır (Berkman ve Reise, 2012). Daha sonra fraksiyonların toprak özellikleri ile olan ilişkileri konvansiyonel korelasyon analizi ile incelenmiştir. Topraklarda belirlenen fosfor fraksiyonları ile tanımlayıcı toprak özelliklerine veri indirgeme yöntemi olan temel bileşen analizi (PCA) uygulanmıştır (SPSS, 2004).

\section{Bulgular ve Tartışma}

\subsection{Fosfor fraksiyonlarının tanımlayıcı istatistikleri}

Toprakların kademeli olarak çözülen, farklı fosfor fraksiyonlarına ait tanımlayıcı istatistikler Çizelge 3'te verilmiştir. Çizelge 2'de fraksiyonların tamamının tipik normal dağılıma sahip olmadığı çarpıklık ve / veya baskklık değeri $\geq 2 \times$ standart hata değerine sahip olmasından anlaşılmaktadır. Genelde çarpıklık katsayısının mutlak değeri fraksiyonun yarayışlılığı ile doğru orantılı olarak değişim göstermiştir. Yani yarayışlılı̆̆ı yüksek $\mathrm{P}$ fraksiyonları $\left(\mathrm{NaHCO}_{3}-\mathrm{Po}\right.$, $\mathrm{NaHCO}_{3}-\mathrm{Pi}$, NaOH-Pi ve NaOH-Po) daha yüksek pozitif çarpıklık göstermektedir. $\mathrm{Bu}$ fraksiyonlardaki pozitif kuyruklanma, topraklarda genel itibarıyla büyük ölçüde yapılan gübreleme uygulamaları ve/veya kısmen toprak oluşum süreçlerinin etkisiyle bazı topraklarda aşırı bir yükselmenin olduğuna işaret etmektedir. $\mathrm{Bu}$ da çalışma sahasının büyüklüğü ve toprak oluşum süreçlerindeki benzerlikler, özellikle iklim ve ana materyalin genelde benzerliği (Akgül ve ark., 2001) göz önüne alındığında yapılan tarımsal uygulamaların etkisini ön plana çıkarmaktadır. Genelde kurak yarı kurak bölgelerde kireçli ana materyal üzerinde oluşan topraklarda yarayışlı $\mathrm{P}$ içeriği düşüktür. Çalışma sahası topraklarında yarayışlı $\mathrm{P}$ olarak kabul edilen Olsen-P $\left(\mathrm{NaHCO}_{3}-\mathrm{Pi}\right) \quad 3.91-96.68 \mathrm{mg} \mathrm{kg}{ }^{-1}$ arasında değişim göstermekte ve ortalaması da $18.68 \mathrm{mg} \mathrm{kg}^{-1}$ dir. $\mathrm{Bu}$ da gösteriyor ki topraklar oldukça yüksek bir kimyasal gübreleme altındadır. Kireçli topraklara aşırı gübreleme yapıldığında muhtemelen $\mathrm{Fe} / \mathrm{Al}$ oksitlerin veya karbonat minerallerinin bolluğuna ve termodinamik koşulların yönetimine bağlı olarak Ca-P ve / veya CBDP'de birikir. Bu durum Ca-P bileşiklerinin alkalin kireçli şartlarda daha stabil ve $\mathrm{Fe}$ çözünürlüğünün düşük olduğu düşünüldüğünde (Lindsay, 1979; Uygur ve Karabatak, 2009) beklenen bir durumdur. Solis ve Torrent (1989) topraktaki fosfor sitrat-bikarbonatditiyonit (CBD) ekstraksiyonu oklüde fosfor fraksiyonunun, $\mathrm{CBD}$ ile ekstrakte edilen $\mathrm{Fe}$ ile ve 
Çizelge 2. Fosfor fraksiyonlarına transformasyon uygulanmadığı durumdaki tanımlayıcı istatistikler (N:71)

\begin{tabular}{|c|c|c|c|c|c|c|c|c|c|c|}
\hline \multirow{2}{*}{$\begin{array}{l}\text { Fraksiyonlar } \\
\left(\mathrm{mg} \mathrm{kg}^{-1}\right)\end{array}$} & \multirow{2}{*}{ Min. } & \multirow{2}{*}{ Maks. } & \multicolumn{2}{|c|}{ Ortalama } & \multirow{2}{*}{$\begin{array}{c}\text { Std. } \\
\text { Sapma }\end{array}$} & \multirow{2}{*}{ Varyans } & \multicolumn{2}{|c|}{ Çarpıklık } & \multicolumn{2}{|c|}{ Basıklık } \\
\hline & & & İstatistik & Std. & & & İstatistik & Std. & İstatistik & Std. \\
\hline $\mathrm{NaHCO}_{3}-\mathrm{Pt}$ & 5.17 & 117.2 & 21.42 & 2.55 & 21.47 & 461.0 & 3.04 & 0.28 & 9.34 & 0.56 \\
\hline $\mathrm{NaHCO}_{3}-\mathrm{Pi}$ & 3.91 & 96.68 & 18.67 & 2.30 & 19.36 & 374.7 & 2.81 & 0.28 & 7.95 & 0.56 \\
\hline $\mathrm{NaHCO}_{3}-\mathrm{Po}$ & 0.27 & 20.52 & 2.75 & 0.43 & 3.65 & 13.34 & 3.16 & 0.28 & 12.11 & 0.56 \\
\hline $\mathrm{NaOH}-\mathrm{Pt}$ & 28.04 & 257.8 & 76.66 & 4.81 & 40.55 & 1644.5 & 2.12 & 0.28 & 6.25 & 0.56 \\
\hline $\mathrm{NaOH}-\mathrm{Pi}$ & 25.99 & 226.6 & 69.43 & 4.47 & 37.69 & 1420.4 & 2.15 & 0.28 & 6.06 & 0.56 \\
\hline $\mathrm{NaOH}-\mathrm{Po}$ & 0.51 & 31.20 & 7.23 & 1.01 & 8.47 & 71.81 & 1.54 & 0.28 & 1.29 & 0.56 \\
\hline CBD-P & 41.78 & 312.6 & 127.5 & 5.88 & 49.54 & 2453.9 & 1.36 & 0.28 & 3.40 & 0.56 \\
\hline Ca-P & 200.2 & 1454.9 & 573.1 & 32.1 & 270.9 & 73420 & 1.16 & 0.28 & 1.55 & 0.56 \\
\hline Res-P & 55.27 & 490.4 & 215.4 & 12.8 & 108.1 & 11690 & 0.92 & 0.28 & -0.10 & 0.56 \\
\hline
\end{tabular}

oklüde P'nin Fe-P minerallerinin kristal örgüsüyle ilişkili olduğunu bildirmiştir.

Düşük çarpıklık ilgili fraksiyondaki göreceli değişimin daha düşük seviyelerde gerçekleștiğini işaret etmektedir. Çoğunlukla primer minerallerden ve organik maddenin yapısında yer alan P'den oluşan Res-P düşük çarpıklık ve negatif basıklık olan tek fraksiyondur. Organik maddeden kaynaklanan etkinin büyük bir kısmı önceki aşamalarda (özellikle de $\mathrm{NaHCO}_{3}$ ve $\mathrm{NaOH}$ gibi alkali ekstraksiyon aşamaları) ayırt edilmiştir. Geride alkali ile çözünmeyen ancak okside olabilen organik maddelerden kaynaklanan bir kısım kalmıștır ki bu da veri setinde göreceli olarak daha düşük çarpıklık katsayısı şeklinde kendini göstermiştir. Walkers ve Syers (1976)'nin önerdiği “conceptual model” e göre Res-P fraksiyonunun önemli bir kısmının apatit formunda olduğu bildirilmektedir.

\subsection{Fosfor fraksiyonlart ve toprak özellikleri arasındaki ilişsiler}

Bazı toprak fiziko-kimyasal özellikleri ile Pfraksiyonları arasındaki Pearson korelasyon katsayıları
Çizelge 5 ve 6 'da verilmiştir. $\mathrm{NaHCO}_{3}-\mathrm{Pi}$ fraksiyonu ile OM miktarı $\left(r=0.617^{* *}\right)$, EC $\left(\mathrm{r}=0.411^{* *}\right)$, kum $(\mathrm{r}=$ $0.259 *), \mathrm{K}(\mathrm{r}=0.369 * *), \mathrm{NaHCO}_{3}-\mathrm{Pt}\left(r=0.98^{* *}\right)$, $\mathrm{NaHCO}_{3}$-Po $\left(r=0.516^{* *}\right)$, NaOH-Pt $(r=0.524 * *)$, $\mathrm{NaOH}-\mathrm{Pi}\left(r=0.780^{* *}\right)$, CBD-P $\left(r=0.465^{* *}\right), \mathrm{Ca}-\mathrm{P}(r$ $\left.=0.457^{* *}\right)$ ve toplam-P $\left(r=0.646^{* *}\right)$ arasinda önemli pozitif korelasyon, kil $\left(r=-0.255^{*}\right)$ içeriği ile önemli negatif korelasyonlar bulunmuştur (Çizelge 3 ve 4). Toprakların $\mathrm{NaHCO}_{3}-\mathrm{Pi}$ ile ekstrakte edilebilir fosfor fraksiyonlarını $\mathrm{OM}, \mathrm{EC}, \mathrm{kum}, \mathrm{K}, \mathrm{NaHCO}_{3}-\mathrm{Pt}$, $\mathrm{NaHCO}_{3}-\mathrm{Po}, \mathrm{NaOH}-\mathrm{Pt}$, NaOH-Pi içeriği, CBD-P, Ca-P ve toplam-P arasındaki pozitif ilişki gübreleme programıyla açıklanabilir. Kil miktarının azalması, yarayışlı fosfor miktarını artırmaktadır ki bunun da adsorpsiyon mekanizmaları ile ilişkili olduğu düşünülebilir. Lyons ve ark. (1998) nehir teras topraklarında inorganik fosforun, adsorpsiyon kapasitesi ve drenaja bağlı olarak değiştiğini bildirmişlerdir.

Maranguit ve ark. (2017) yarayışlılı̆̆ yüksek P fraksiyonlar1 $\left(\mathrm{H}_{2} \mathrm{O}-\mathrm{Pi}, \mathrm{NaHCO}_{3}-\mathrm{Pi}\right.$ ve $\left.\mathrm{Po}\right)$ ile toplam organik P miktarı ve karbon içeriği arasında güçlü bir pozitif korelasyon tespit etmiştir.

Çizelge 3. Fosfor fraksiyonları ve bazı toprak özellikleri arasındaki Pearson korelasyon matrisi (N:71)

\begin{tabular}{lccc|ccccccc}
\hline & \multicolumn{9}{c}{ Fosfor Fraksiyonlar1 } \\
\cline { 2 - 10 } Toprak & \multicolumn{3}{c}{$\mathrm{NaHCO}_{3}$} & \multicolumn{3}{c}{$\mathrm{NaOH}$} & & & & \\
Özellikleri & $\mathrm{Pt}$ & $\mathrm{Pi}$ & $\mathrm{Po}$ & $\mathrm{Pt}$ & $\mathrm{Pi}$ & $\mathrm{Po}$ & CBD-P & Ca-P & Res-P & Top-P \\
\hline OM & $0.65^{* *}$ & $0.61^{* *}$ & $0.56^{* *}$ & $0.62^{* *}$ & $0.61^{* *}$ & $0.25^{*}$ & $0.46^{* *}$ & $0.50^{* *}$ & $0.29^{*}$ & $0.63^{* *}$ \\
Kireç & 0.14 & 0.13 & 0.13 & 0.06 & 0.08 & -0.08 & 0.02 & $0.31^{* *}$ & -0.02 & 0.22 \\
Aktif & 0.16 & 0.14 & 0.21 & 0.11 & 0.14 & -0.06 & 0.13 & $0.47^{* *}$ & 0.21 & $0.41^{* *}$ \\
pH & -0.09 & -0.08 & -0.10 & -0.20 & -0.18 & -0.18 & -0.13 & $0.25^{*}$ & -0.12 & 0.07 \\
EC & $0.39^{* *}$ & $0.41^{* *}$ & 0.14 & 0.16 & 0.19 & -0.09 & -0.05 & 0.19 & 0.03 & 0.19 \\
Kum & $0.24^{*}$ & $0.25^{*}$ & 0.06 & $0.27^{*}$ & $0.26^{*}$ & 0.11 & 0.06 & 0.17 & -0.06 & 0.18 \\
Silt & -0.1 & -0.10 & 0.01 & -0.10 & 0.02 & -0.11 & 0.08 & 0.05 & 0.03 & 0.02 \\
Kil & $-0.24^{*}$ & $-0.25^{*}$ & -0.08 & $-0.28^{*}$ & $-0.29^{*}$ & -0.06 & -0.13 & $-0.26^{*}$ & 0.05 & $-0.24^{*}$ \\
KDK & -0.03 & -0.03 & -0.02 & -0.09 & -0.08 & -0.11 & -0.11 & -0.01 & $0.29 *$ & 0.03 \\
Ca & -0.01 & -0.01 & 0.02 & -0.17 & -0.15 & -0.16 & -0.18 & 0.12 & 0.14 & 0.05 \\
K & $0.34^{* *}$ & $0.36^{* *}$ & 0.081 & $0.255^{*}$ & $0.282^{*}$ & -0.034 & 0.094 & $0.36^{* *}$ & 0.14 & $0.36^{* *}$ \\
Mg & 0.008 & 0.007 & 0.01 & 0.03 & 0.008 & -0.04 & 0.024 & $0.24^{*}$ & 0.16 & 0.20 \\
Na & 0.128 & 0.137 & 0.028 & 0.216 & 0.165 & $0.30^{*}$ & 0.125 & -0.09 & -0.18 & -0.03 \\
$\mathrm{P}$ & $0.98^{* *}$ & $1.00^{* *}$ & $0.51^{* *}$ & $0.76^{* *}$ & $0.78^{* *}$ & 0.169 & $0.46^{* *}$ & $0.45^{* *}$ & 0.229 & $0.64^{* *}$ \\
\hline
\end{tabular}


$\mathrm{NaHCO}_{3}$-Po ile toprak özelliklerinden $\mathrm{OM}$ miktarı $\left(r=0.569^{* *}\right)$; fosfor fraksiyonlarından $\mathrm{NaHCO}_{3}-\mathrm{Pt}(r=$ $\left.0.635^{* *}\right), \mathrm{NaHCO}_{3}-\mathrm{Pi}\left(r=0.516^{* *}\right), \mathrm{NaOH}-\mathrm{Pt}(r=$ $0.524 * *), \quad \mathrm{NaOH}-\mathrm{Pi}(r=0.537 * *)$, CBD-P $(r=$ $0.529 * *)$, Ca-P $(r=0.336 * *)$ ve toplam-P $(0.472 * *)$ arasında önemli pozitif korelasyonlar belirlenmiştir (Çizelge 3 ve 4). Bu ilişkilerin ortaya çıkmasında topraklarda organik maddenin artmasına bağlı olarak -ki bu genelde çok yıllık bitkilerin özellikle meyve ağaçlarının arazide bulunması ile ilgilidir- arazilerin artan miktarda gübrelenmesinin sonucunda ortaya çıkmış olabileceğine işaret etmektedir. Nitekim Alovisi ve ark. (2016), inorganik P gübrelemelerinin orta derece labil ve labil $\mathrm{P}$ fraksiyonlarını önemli derecede arttırdığını göstermiştir. Diğer taraftan yarayışlı fosfora en fazla katkının organik P fraksiyonlarından $\mathrm{NaHCO}_{3}-$ Po fraksiyonundan kaynaklandığını bildirmişlerdir ki bu çalışmada yarayış̧ı P ile bu fraksiyon arasında yüksek korelasyon katsayısı bulunmuştur (Çizelge 3).

Çizelge 4. Fosfor fraksiyonları arasındaki Pearson korelasyon matrisi (N:71)

\begin{tabular}{|c|c|c|c|c|c|c|c|c|c|c|}
\hline \multirow{3}{*}{\multicolumn{2}{|c|}{$\begin{array}{l}\text { Fosfor } \\
\text { Fraksiyonlar1 }\end{array}$}} & \multicolumn{2}{|c|}{$\mathrm{NaHCO}_{3}-\mathrm{P}$} & \multicolumn{3}{|c|}{ NaOH-P } & \multirow{2}{*}{ CBD-P } & \multirow{2}{*}{$\mathrm{Ca}-\mathrm{P}$} & \multirow{2}{*}{ Res-P } & \multirow{2}{*}{ Toplam-P } \\
\hline & & $\mathrm{Pi}$ & $\mathrm{Po}$ & $\mathrm{Pt}$ & $\mathrm{Pi}$ & Po & & & & \\
\hline & & \multicolumn{9}{|c|}{$\left(\mathrm{mg} \mathrm{kg}^{-1}\right)$} \\
\hline \multirow{3}{*}{ 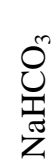 } & $\mathrm{Pt}$ & $0.989 * *$ & $0.635^{* *}$ & $0.775^{* *}$ & $0.795 * *$ & 0.170 & $0.509^{* *}$ & $0.469 * *$ & 0.230 & $0.663 * *$ \\
\hline & $\mathrm{Pi}$ & & $0.516^{* *}$ & $0.760^{* *}$ & $0.780 * *$ & 0.170 & $0.465^{* *}$ & $0.457^{* *}$ & 0.230 & $0.646 * *$ \\
\hline & Po & $0.516^{* *}$ & & $0.524 * *$ & $0.537 * *$ & 0.120 & $0.529 * *$ & $0.336^{* *}$ & 0.130 & $0.472 * *$ \\
\hline \multirow{3}{*}{$\begin{array}{l}T \\
0 \\
\text { Z } \\
Z\end{array}$} & $\mathrm{Pt}$ & 0.760 ** & $0.524 * *$ & & $0.979 * *$ & $0.431 * *$ & $0.551^{* *}$ & $0.543 * *$ & 0.150 & $0.716^{* *}$ \\
\hline & $\mathrm{Pi}$ & $0.780 * *$ & $0.537 * *$ & $0.979 * *$ & & $0.238^{*}$ & $0.551^{* *}$ & $0.555^{* *}$ & 0.200 & $0.733 * *$ \\
\hline & Po & 0.170 & 0.120 & $0.431^{* *}$ & $0.238^{*}$ & & 0.190 & 0.130 & -0.150 & 0.170 \\
\hline \multicolumn{2}{|c|}{ CBD-P } & $0.465 * *$ & $0.529 * *$ & $0.551^{* *}$ & $0.551^{* *}$ & 0.190 & & $0.421 * *$ & 0.230 & $0.598^{* *}$ \\
\hline \multicolumn{2}{|c|}{$\begin{array}{l}\text { Ca-P } \\
\text { Res-P }\end{array}$} & $0.457 * *$ & $0.336 * *$ & $0.543 * *$ & $0.555^{* *}$ & 0.130 & $0.421 * *$ & & $0.352 * *$ & $0.924 * *$ \\
\hline \multicolumn{2}{|c|}{ Res-P } & 0.230 & 0.130 & 0.150 & 0.200 & -0.150 & 0.230 & $0.352^{* *}$ & & $0.556 * *$ \\
\hline \multicolumn{2}{|c|}{ Toplam-P } & $0.646 * *$ & $0.472 * *$ & $0.716^{* *}$ & $0.733 * *$ & 0.170 & $0.598^{* *}$ & $0.924 * *$ & $0.556^{* *}$ & \\
\hline
\end{tabular}

$\mathrm{NaOH}-\mathrm{Pi}$ fraksiyonu ile OM miktarı $\left(r=0.616^{* *}\right)$, $\operatorname{kum}\left(\mathrm{r}=0.269^{*}\right), \mathrm{K}\left(\mathrm{r}=0.369^{* *}\right), \mathrm{NaHCO}_{3}-\mathrm{Pt}(r=$ $\left.0.795^{* *}\right), \mathrm{NaHCO}_{3}-\mathrm{Pi}\left(r=0.780^{* *}\right), \mathrm{NaHCO}_{3}-\mathrm{Po}(r=$ $0.524 * *), \mathrm{NaOH}-\mathrm{Pt}(r=0.979 * *), \mathrm{NaOH}-\mathrm{Po}(r=$ $\left.0.238^{*}\right)$, CBD-P $\left(r=0.551^{* *}\right)$, Ca-P $\left(r=0.457^{* *}\right)$ ve toplam-P $\left(r=0.733^{* *}\right)$ arasında önemli pozitif korelasyonlar, kil $\left(\mathrm{r}=-0.255^{*}\right)$ önemli negatif korelasyon bulunmuştur (Çizelge 3 ve 4). Toprakların $\mathrm{NaOH}-\mathrm{Pi}$ ile ekstrakte edilebilir fosfor fraksiyonlarının $\mathrm{OM}$, kum, K, $\mathrm{NaHCO}_{3}-\mathrm{Pt}, \mathrm{NaHCO}_{3}-\mathrm{Pi}, \mathrm{NaHCO}_{3}-\mathrm{Po}$, $\mathrm{NaOH}-\mathrm{Pt}, \mathrm{NaOH}-\mathrm{Po}$ içeriği, CBD-P, Ca-P ve toplam-P arasındaki pozitif ilișki bu fraksiyonun bağlandığı yüzeylerle (genellikle $\mathrm{Fe}$ ve $\mathrm{Al}, \mathrm{OH}$ yüzeylerine bağlanır), artan kil miktarıyla azalması ise ilave edilen fosforun kil mineralleri tarafindan adsorbe edilmesinin bir fonksiyonudur. Uygur ve ark. (2017) yapmış oldukları çalışmada CBD ile ekstrakte edilebilen Fe ve $\mathrm{Al}$ ile NaOH-Pi arasında önemli ilișkiler belirlemişlerdir. Özellikle fazla gübreleme yapılan arazilerde toprağa ilave edilen $\mathrm{P}$, öncelikle adsorpsiyon reaksiyonlarıyla ya da çökelme reaksiyonlarıyla tamponlanmaktadır. $\mathrm{Bu}$ açıdan oksit minerallerin yüzeyleri mineral P'nin adsorpsiyonunda önemli bir bileşendir (He ve ark., 1994; Violante ve ark., 2002; Wei ve ark., 2014).

NaOH-Po fraksiyonu ile OM miktarı $\left(r=0.254^{*}\right)$, $\mathrm{Na}\left(r=0.300^{*}\right), \mathrm{NaOH}-\mathrm{Pt}\left(r=0.431^{* *}\right)$ ve NaOH-Pi $(r$ $\left.=0.238^{*}\right)$ arasında önemli pozitif korelasyonlar bulunmuștur (Cizelge 3 ve 4). Elde edilen bu korelasyon katsayıları temelde farklı nedenlerle açıklanabilir: i)
$\mathrm{NaOH}$ alkali olması nedeniyle önemli miktarlarda organik maddeyi ekstrakte edebilmektedir. ii) organik madde veya toprak organik maddesinin humik asit ve fulvik asit gibi fraksiyonları topraktaki adsorpsiyon yüzeyleri için fosfat iyonlarıyla rekabet halindedir. YiChao ve ark. (2015), $\mathrm{NaHCO}_{3}$ ile ekstrakte edilebilir inorganik $\mathrm{P}$ ve $\mathrm{NaOH}$ ile ekstrakte edilebilen organik P'nin, fosforlu gübrelemeyle önemli ölçüde ilişkili olduğunu göstermiştir.

CBD-P fraksiyonu ile OM miktarı $\left(r=0.469^{* *}\right)$, yarayışlı fosfor $\left(r=0.465^{*}\right), \mathrm{NaHCO}_{3}-\mathrm{Pt}(r=$ $\left.0.509^{* *}\right), \mathrm{NaHCO}_{3}-\mathrm{Pi}\left(r=0.465^{* *}\right), \mathrm{NaHCO}_{3}-\mathrm{Po}(r=$ $\left.0.529^{*}\right), \mathrm{NaOH}-\mathrm{Pt}\left(r=0.551^{*}\right), \mathrm{NaOH}-\mathrm{Pi}(r=$ $\left.0.551^{* *}\right)$, Ca-P $\left(r=0.421^{* *}\right)$ ve toplam-P $\left(r=0.598^{* *}\right)$ arasında önemli pozitif korelasyonlar bulunmuştur (Çizelge 3 ve 4). Zira herhangi bir toprağa ne kadar fazla gübre uygulanırsa kısa vadede yarayışlıllğ̆ yüksek olan fraksiyonlarda $\left(\mathrm{NaHCO}_{3}\right.$ ve $\mathrm{NaOH}$ ile ekstrakte edilebilen fraksiyonlar) uzun vadede ise yüksek miktardaki ilavelerin tamponlanmasına dönük çözünürlüğü düşük fraksiyonlarda (CBD-P, Ca-P ve toplam P) artış gerçekleşir (Uygur ve Karabatak, 2009).

Ca-P fraksiyonu ile OM miktarı $\left(r=0.502^{* *}\right)$, kireç $\left(r=0.314^{* *}\right)$, aktif kireç $\left(r=0.473^{* *}\right), \mathrm{pH}\left(r=0.257^{*}\right)$, yarayışılı $\mathrm{K}\left(r=0.365^{* *}\right)$, yarayışlı $\mathrm{Mg}\left(r=0.246^{*}\right)$, yarayışlı fosfor $(r=0.457 * *), \mathrm{NaHCO}_{3}-\mathrm{Pt}(r=$ $\left.0.469^{* *}\right), \mathrm{NaHCO}_{3}-\mathrm{Pi}\left(r=0.457^{* *}\right), \mathrm{NaHCO}_{3}-\mathrm{Po}(r=$ $\left.0.336^{* *}\right), \mathrm{NaOH}-\mathrm{Pt}\left(r=0.543^{* *}\right), \mathrm{NaOH}-\mathrm{Pi}(r=$ $\left.0.555^{*}\right)$, CBD-P $(r=0.421 * *)$, Res-P $(r=0.352 * *)$ ve toplam-P $\left(r=0.924^{* *}\right)$ arasında önemli pozitif 
korelasyonlar, kil $(r=-0.264 *)$ önemli negatif korelasyon bulunmuştur (Çizelge 3 ve 4). Toprakların $\mathrm{Ca}-\mathrm{P}$ ile ekstrakte edilebilir fosfor fraksiyonlarının OM olan ilişkisi bitki örtüsünden kaynaklanan gübreleme uygulamaları ile açıklanabilir. Diğer özelliklerle olan pozitif korelasyonlar yörede uygulanan aşırı fosforlu gübrelemenin bir sonucu olarak kısa ve uzun vadede tamponlama yapan fraksiyonlardaki artış ile ilişkili olduğu düşünülebilir. Negatif ilişkiler ise ilave edilen P' nin Ca-P fraksiyonunda birikmesine engel olan toprak özellikleriyle ilgilidir. Nitekim bu çalışmada Ca-P fraksiyonu ile kil özellikleri arasında negatif ilişkiler bulunmuştur. Yani söz konusu toprak bileşenlerinin yüksek olduğu durumlarda toprağa ilave edilen P'nin Ca-P fraksiyonu yerine kil yüzeylerinde adsorbe edildiğinin bir işaretidir. Patiram ve ark. (1990) asit topraklarda P'nin ağırlıklı olarak CBD-P fraksiyonunda bulunduğunu. Al-P ve Ca-P'nin fraksiyonlarının önemli miktarda değişmediğini bulmuşlardır. Tandon (1987), nötr-alkalin topraklarda toplam P'nin yaklaşık \% 4050'sini Ca-P fraksiyonunun oluşturduğunu ve hatta kireçli topraklarda bu oranın \% 50'nin de üzerine çıktığının bildirmişlerdir. Bu bağlamda bu araştırmada tespit edilen aktif kireç ile Ca-P arasındaki yüksek ilişki Ca-P'nin bu topraklarda stabil bir fosfor fraksiyonu olduğunu göstermektedir.

Res-P fraksiyonu ile OM miktarı $\left(r=0.291^{*}\right)$, KDK $\left(r=0.295^{*}\right)$, Ca-P $\left(r=0.352^{* *}\right)$ ve toplam-P $(r=$ $\left.0.556^{* *}\right)$ arasinda önemli pozitif korelasyon bulunmuştur (Çizelge 3 ve 4). KDK ile olan ilişki toprak oluşum süreçlerinde P'yi tutabilme yeteneği yüksek kil minerallerinden dolayı bir artışa işaret ederken, $\mathrm{OM}$ ile olan ilişki topraklarda gerek genetik gerekse amenajman kaynaklı organik madde artışında toplam fosforun önemli bir kısmının organik madde içerisinde yer aldığına işaret etmektedir. Patiram ve ark. (1990), ResP'nin toplam ve organik $\mathrm{P}$ ile yüksek oranda ilişkili olduğunu, ancak diğer inorganik P formlarıla negatif bir ilişkiye sahip olduğunu bildirmiştir. Bu yaklaşımın tersi düşünüldüğünde aşırı gübreleme yapıldığında topraklarda termodinamik açıdan stabil olan apatit mineralinin oluşması söz konusu olabilir. Gerek ayrışmanın göreceli olarak daha az gerçekleştiği gerekse aşırı gübrelemenin yaygın olduğu çalışma alanı topraklarında Res-P'nin yüksek olması bu bağlamda beklenen bir durumdur. Shukla ve ark. (2016) ve Uygur ve ark. (2017) yapmış oldukları çalışmalarda kireçli topraklarda Res-P'nin göreceli olarak yüksek miktarlarda bulunduğunu tespit etmişlerdir.

Toplam-P NaOH-Po dişındaki tüm diğer fraksiyonlarda çok önemli korelasyon katsayıları vermiştir. En yüksek korelasyon katsayıları ise Ca-P $(0.924 * *)$ ve $\mathrm{NaOH}-\mathrm{Pi}\left(0.733^{* *}\right)$ fraksiyonlarında elde edilmiştir. $\mathrm{Bu}$ durum, topraklara ilave edilen inorganik fosforun orta dereceli yarayışlı NaOH-Pi ya da Fe ve $\mathrm{Al}$ oksit yüzeylerinde oklüde olmadan tutulduğunu sonraki aşamada ise kireçli topraklarda termodinamik açıdan stabil olan Ca-P fraksiyonuna (Lindsay, 2001; Uygur ve Karabatak, 2009) dönüştüğüne işaret etmektedir. $\mathrm{NaHCO}_{3}-\mathrm{P}$ fraksiyonlarıyla olan yüksek ilişki ise toprakların aşırı fosforlu gübre altında olduğunun bir belirtisi kabul edilebilir.

\subsection{Kemometrik iliş̧kiler}

Topraklarda belirlenen fosfor fraksiyonları ile tanımlayıcı toprak özelliklerine veri azaltma yöntemi olan temel bileşen analizi (PCA) uygulanmıştır. SPSS'in varimax rotasyon rutini ile korelasyon matrisi kullanılarak özdeğeri 1'den büyük olan 6 ayrı temel bileşen elde edilmiştir (Çizelge 5). Bu bileşenlerle toplamda meydana gelen varyansin \% 77.37'si açıklanabilmektedir. Temel bileşenler (PC1-6) toplam varyansin sirasiyla $\% 28.96,21.49,9.41,6.65,6.03$ ve 4.81'lik bir kısmını açıklayabilmektedir. İzole edilen 6 bileşenden dördü, P fraksiyonlarının açık kavramsal gruplamaları ile bağlantılı olarak, ilgili fraksiyonları etkileyen bazı toprak özellikleri ile ilişkilidir: PC1, $\mathrm{NaHCO}_{3}-\mathrm{Pt}, \quad \mathrm{NaHCO}_{3}-\mathrm{Pi}, \quad \mathrm{NaHCO}_{3}-\mathrm{Po}, \quad \mathrm{NaOH}-\mathrm{Pt}$, $\mathrm{NaOH}-\mathrm{Pi}$ ， CBD-P, Ca-P, Res-P ve toplam-P; PC4 $\mathrm{NaOH}-\mathrm{Po}$, Ca-P, Res-P ve toplam-P; PC5 $\mathrm{NaHCO}_{3}-\mathrm{Po}$ ve CBD-P ve PC $6 \mathrm{NaOH}-\mathrm{Po}$ ile yüksek yükleme değerlerine sahiptir. PC2 ve PC3 ayrıca, toprakların fizikokimyasal özelliklerinin P fraksiyonlarına etkisini açıklamaktadır (Çizelge 6). PC1 ve PC2'nin dağılım grafiği incelendiğinde bazı toprakların önemli farklılıklar gösterdiği anlaşılmaktadır. " 0 " dan geçen hatlar aslında temel bileşenlerinin en etkili olduğu hattı göstermektedir. $\mathrm{Bu}$ açıdan $\mathrm{X}$ eksenine paralel " 0 " noktasında geçen hattın negatif ucunda yer alan topraklar $(44,41,40)$ PC1 ile negatif yükleme değerleri veren toprak özelikleriyle -ki bu açıdan herhangi bir toprak özelliği -0.3'ün üzerinde dikkate değer bir yükleme değerine sahip değildir- (Çizelge 6); hattın sağ ucunda yer alan topraklar $(55,9,33,64,63)$ ise PC1 ile pozitif yükleme değerleri veren toprak özellikleri nedeniyle farklılık göstermektedir. Bu özelliklere ilave olarak kısmen toprak amenajman pratiklerinin kısmen de toprak oluşum süreçlerinin etkisi altında olan $\mathrm{OM}$ (0.747) pozitif yükleme değerine sahiptir (Çizelge 6). $\mathrm{Bu}$ da toprakların fosfor yarayışlılığında OM maddenin önemli bir katkısının olduğunu göstermektedir. Nitekim yapılan çalışmalar topraklara organik madde ilavesinin yarayışı P miktarını arttırdığııı bildirmektedir (Uygur ve Karabacak, 2009).

Y eksenine paralel " 0 " noktasında geçen hattın negatif ucunda yer alan topraklar $(4,54,46,65)$ PC2 ile negatif yükleme değerleri veren toprak özelikleriyle yani; kum ve Na miktarı ile hattın üst ucunda yer alan topraklar $(60,71)$ ise PC2 ile pozitif yükleme değerleri veren toprak özeliklerinden kireç, aktif kireç, $\mathrm{EC}, \mathrm{pH}$, silt, kil, KDK, yarayışlı K, Ca ve Mg değişkenlerinin etkisi altındadır (Şekil 1). 
Çizelge 5. Temel bileşenlerle açılanan özdeğeri “1”den büyük olan varyanslar

\begin{tabular}{lcccccc}
\hline \multirow{2}{*}{ Bileşenler } & \multicolumn{3}{c}{ Basslangıc Özdeğerleri } & \multicolumn{2}{c}{ Döndürülmüs Kareli Yüklerin Toplamı } \\
\cline { 2 - 6 } & Toplam & \% Varyans & \% Kümülatif & Toplam & \% Varyans & \% Kümülatif \\
\hline 1 & 6.662 & 28.964 & 28.964 & 6.662 & 28.964 & 28.964 \\
2 & 4.943 & 21.490 & 50.454 & 4.943 & 21.490 & 50.454 \\
3 & 2.166 & 9.419 & 59.874 & 2.166 & 9.419 & 59.874 \\
4 & 1.530 & 6.651 & 66.525 & 1.530 & 6.651 & 66.525 \\
5 & 1.388 & 6.034 & 72.559 & 1.388 & 6.034 & 72.559 \\
6 & 1.107 & 4.813 & 77.372 & 1.107 & 4.813 & 77.372 \\
\hline
\end{tabular}

Kumun yüksek olması, kolayca yıkanmayı sağlayıp fosforun toprakta tutulmasinı önlemektedir. Sodyum ise organik maddenin çözünürlüğünü arttırarak adsorpsiyon yüzeylerinde yarayışlı $\mathrm{P}$ ile rekabete neden olabilmektedir. Özellikle $\mathrm{NH}_{4}$-asetat ile ekstrakte edilebilir Ca miktarı KDK ile birlikte, ki en yüksek yükleme değerlerini vermiştir, P'nin toprakta yarayışsız olarak tutulmasında en önemli etkenlerdendir (Akinremi ve Cho, 1991) ve Ca-P kireçli alkalin topraklarda termodinamik açıdan en stabil P katı fazıdır (Lindsay, 2001; Uygur ve Karabatak, 2009). "0" eksenlerinden uzaktaki noktalar her iki bileşen ile yüksek yükleme değerine sahip toprak özellikleri nedeniyle ayrımlıdır. Örneğin 35, 42, 47 nolu topraklar her iki bileşenle negatif yükleme değeri veren toprak özelliklerinin bir fonksiyonu olarak diğer topraklardan farkl1lik göstermektedir. 19, 20 ve 21 nolu topraklar ise PC1 ile negatif PC2 ile pozitif yükleme değerleri nedeniyle ayrımlıdır. $\mathrm{Bu}$ topraklar " 0 " eksenlerine uzaklığı derecesinde temel bileşenin ilgili toprak özelliklerine ait yükleme derecesindeki payı artmaktadır.

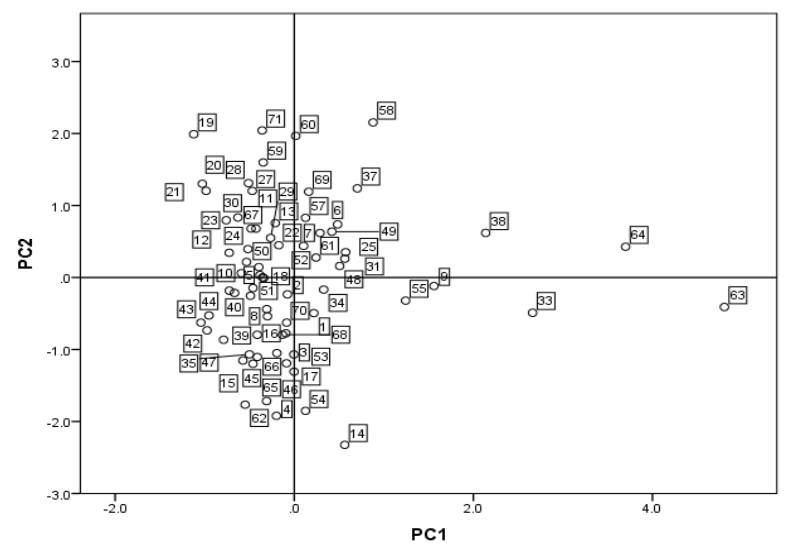

Şekil 1. PC1 ve PC2 ile ilişkili parametreler çerçevesinde toprakların dağılımı

Çizelge 6. Temel bileşenlerle toprak özellikleri arasındaki yükleme matrisi*

\begin{tabular}{|c|c|c|c|c|c|c|}
\hline \multirow{2}{*}{ Toprak özellikleri } & \multicolumn{6}{|c|}{ Temel bileșenler } \\
\hline & PC1 & $\mathrm{PC} 2$ & $\mathrm{PC} 3$ & PC4 & PC5 & PC6 \\
\hline $\mathrm{NaHCO}_{3}-\mathrm{Pt}$ & 0.891 & & & & & \\
\hline $\mathrm{NaHCO}_{3}-\mathrm{Pi}$ & 0.865 & & & & & \\
\hline $\mathrm{NaHCO}_{3}$-Po & 0.654 & & & & -0.315 & \\
\hline $\mathrm{NaOH}-\mathrm{Pt}$ & 0.880 & & & & & \\
\hline $\mathrm{NaOH}-\mathrm{Pi}$ & 0.888 & & & & & \\
\hline NaOH-Po & & & & 0.327 & & 0.622 \\
\hline CBD-P & 0.646 & & & & -0.382 & \\
\hline Ca-P & 0.741 & & & -0.333 & & \\
\hline Res-P & 0.352 & & & -0.656 & & \\
\hline Toplam-P & 0.892 & & & -0.352 & & \\
\hline OM & 0.778 & & & & & \\
\hline Kireç & & 0.317 & 0.775 & & & \\
\hline Aktif Kireç & 0.338 & 0.589 & 0.454 & & & \\
\hline pH & & 0.522 & 0.542 & & 0.398 & \\
\hline EC & 0.315 & 0.589 & & 0.427 & 0.379 & \\
\hline Kum & & -0.827 & & & 0.402 & \\
\hline Silt & & 0.579 & 0.416 & & -0.375 & \\
\hline Kil & & 0.635 & -0.527 & & & \\
\hline KDK & & 0.803 & -0.484 & & & \\
\hline Ca & & 0.915 & & & & \\
\hline $\mathbf{K}$ & 0.387 & 0.496 & & & 0.399 & \\
\hline Mg & & 0.516 & & & & 0.531 \\
\hline $\mathbf{N a}$ & & -0.467 & & 0.524 & & \\
\hline
\end{tabular}




\section{Sonuç}

Atabey Ovası'ndan 20 toprak serisinden alınan toplam 71 adet toprak örneğinde tanımlayıcı detaylı analizler yapılmıştır. Tanımlayıcı analizler topraklarda OM'nin ve yarayışlı P özelliklerinin bitki örtüsü ve aşırı gübreleme nedeniyle dikkate değer bir artma eğiliminde olduğunu göstermiştir. Ova topraklarında fraksiyonların ortalama dağılım sırası büyükten küçüğe doğru; Ca-P $(\%$ 50.36) > Res-P (\% 19.94) > CBD-P (\% 12.17) > $\mathrm{NaOH}-\mathrm{Pt}\left(\%\right.$ 6.94) $>\mathrm{NaOH}-\mathrm{Pi}\left(\%\right.$ 6.24) $>\mathrm{NaHCO}_{3}-\mathrm{Pt}$ $\left(\%\right.$ 1.82) $>\mathrm{NaHCO}_{3}-\mathrm{Pi}(\%$ 1.57) $>\mathrm{NaOH}-\mathrm{Po}(\%$ 0.71) $>$ $\mathrm{NaHCO}_{3}$-Po (\% 0.25) şeklinde izlenmiştir. Topraklarda potansiyel olarak yarayışlılığı yüksek olan fraksiyonların ortalama miktarının (NaOH-Pt + $\mathrm{NaHCO}_{3}-\mathrm{Pt}$ ) \% 8.76 olduğu bu değer de göreceli olarak bazı topraklarda anormal derecede, çevre kirliliğine neden olabilecek seviyede, yüksek olduğunu göstermektedir. Bu çalışmanın sonuçları, ayrıca Atabey Ovası topraklarındaki eksiklik / toksisite mekanizmalarını anlamak için önemli bir veri tabanı oluşturmuştur.

\section{Teșekkür}

Bu çalışma Süleyman Demirel Üniversitesi Bilimsel Araştırma Koordinasyon Birimi tarafından 4886-YL117 nolu yüksek lisans projesi kapsamında desteklenmiştir.

\section{Kaynaklar}

Achat, D.L., Pousse, N., Nicolas, M., Brédoire, F., Augusto. L., 2016. Soil properties controlling inorganic phosphorus availability: general results from a national forest network and a global compilation of the literature. Biogeochemistry. 127(2): 255-272. doi: 10.1007/s10533-015-0178-0.

Akinremi, O.O., Cho, C.M., 1991. Phosphate and accompanying cation transport in a calcareous cation-exchange resin system. Soil Science Society of America Journal, 55 (4): 959-964. doi.10.2136/sssaj1991.03615995005500040010

Akgül, M., Başayiğit, L., Uçar, Y., Müjdeci, M., 2001. Atabey Ovası toprakları. Süleyman Demirel Üniversitesi Yayınları, 71s, Isparta.

Alovisi, A.M.T., Neto, A.E.F., Serra, A.P., Alovisi, A.A., Tokura, L.K., Lourente, E.R.P., da Silva, R.S., da Silva, C.F.B., Fernandes, J.S., 2016. Phosphorus and silicon fertilizer rates effects on dynamics of soil phosphorus fractions in oxisol under common bean cultivation. African Journal of Agricultural Research, 11(30): 2697-2707. doi.10.5897/ajar2016.11304.

Berkman, E. T., Reise, S. P., 2012. A conceptual guide to statistics using SPSS. Sage ISO 690.

Dieter, D., Elsenbeer, H., Turner, B.L., 2010. Phosphorus fractionation in lowland tropical rainforest soils in Central Panama. Catena, 82 (2): 118-125. doi.org/10.1016/j.catena.2010.05.010.

Durgun, B., 2016. Atabey Ovası'ndaki toprak serilerinde çinko fraksiyonlarının belirlenmesi. Süleyman Demirel Üniversitesi, Fen Bilimleri Enstitüsü, Yüksek Lisans Tezi, 92s, Isparta.

Drouineau, G., 1942. Dosage rapide du calcaire actif de sols. Nouvelles donnes sur la repatition et la nature des fractions calcaires. Annales de Agronomie, 12: 441-450.

Gee, G.W., Bauder, J.W., 1986. Particle-size analysis. In: Klute A. (ed.). Methods of soil analysis. Part 1. 2nd ed. Agron. Monogr. 9. ASA and SSSA, Madison, WI., USA. pp. 383-411.

Halajnia, A., Haghnia, G.H., Fotovat, A., Khorasani, R., 2009. Phosphorus fractions in calcareous soils amended with $\mathrm{P}$ fertilizer and cattle manure. Geoderma, $150 \quad$ (1): 209-213. doi.org/10.1016/j.geoderma.2009.02.010.

Hedley, M.J., Stewart, J.W.B., Chauhan, B.S., 1982. Changes in inorganic and organic soil-phosphorus fractions induced by cultivation practices and by laboratory incubations. Soil Science Society of America Journal, 46: 970-976. doi.10.2136/sssaj1982.03615995004600050017x.

He, Z. L., Yang, X., Yuan, K. N., Zhu, Z. X., 1994. Desorption and plant-availability of phosphate sorbed by some important minerals. Plant Soil, 162 (1): 89-97.

Karaman, M.R., 2012. Bitki besleme. Gaziosmanpaşa Üniversitesi Ziraat Fakültesi Yayınları, Yayın No: 14021, 1066s, Ankara.

Kacar, B., Katkat, A.V., 2009. Bitki besleme. Ankara Üniversitesi Ziraat Fakültesi Yayınları, Yayın No: 849, 659s, Ankara.

Kacar, B., 2013. Temel gübre bilgisi. Ankara Üniversitesi Ziraat Fakültesi Yayınları, Yayın No: 695, 502s, Ankara.

Korkmaz, K., 2005. Kireçli toprakların fosfor durumlarının belirlenmesi ve fosfor uygulamasının mısır verimine etkisi. Çukurova Üniversitesi, Fen Bilimleri Enstitüsü, Doktora Tezi, 136s, Adana.

Kuo, S. 1996. Phosphorus. In: Sparks, DL (ed.). Methods of soil analysis, Part 3, Chemical methods. Soil Science Society of America, Series No: 5, WI, USA. pp. 869-920.

Lindsay, W.L., 1979. Chemical equilibria in soils. John Wiley and Sons, New York, USA.

Lindsay, W.L., 2001. Chemical equilibria in soils. The Blackburn Press, USA.

Lyons, J.B., Gorres, J.H., Amador J.A., 1998. Spatial and temporal variability of phosphorus retention in a riparian forest soil. Journal of Environmental Quality, 27: 895-903. doi:10.2134/jeq1998.00472425002700040025x.

Maranguit, D., Guillaume, T., Kuzyakov, Y., 2017. Land-use change affects phosphorus fractions in highly weathered tropical soils. Catena, 149: 385-393. doi.org/10.1016/j.catena.2016.10.010. 
Murphy, J., Riley, J.P., 1962. A modified single solution method for the determination of phosphate in natural waters. Analytica Chimica Acta, 27: 31-36. doi.org/10.1016/S0003-2670(00)88444-5.

Nelson, D.W., Sommers, L.E., 1982. Total carbon, organic carbon and organic matter. In: Page, A.L. et al (Eds). Methods of soil analysis, Part 2. Chemical and microbiological properties. Second Edition, Soil Science Society of America, Agronomy No: 9, WI, USA. pp. 539-579.

Olsen, S.R., Cole, C.V., Watanabe F.S., Dean. L.A., 1954. Estimation of available phosphorus in soils by extraction with sodium bicarbonate. US. Department of Agriculture, Circ. 939.

Patiram, R.N., Raj, M.M., Prasad, R.N., 1990. Forms of soil phosphorus and suitable extactants for available phosphorus in acid soils of Sikkim. Journal of Indian Society of Soil Science, 38 (1): 237-242.

Rhoades, J.D., 1982. Cation exchange capacity. In: Page, A.L. et al (Eds). Methods of soil analysis, Part 2. Chemical and microbiological properties. Second Edition, Soil Science Society of America, Agronomy No: 9, WI, USA. pp. 149-147.

Saltalı, K., Kılıç, K., Koçyigit, R., 2007. Changes in sequentially extracted phosphorus fractions in adjacent arable and grassland ecosystems. Arid Land Research and Management, 21(1):81-89. doi.org/10.1080/15324980601074602.

SPSS, I., 2004. SPSS 13.0 for windows. Chicago, Illinois, USA.

Solis, P., Torrent, J., 1989. Phosphate fractions in calcareous Vertisols and Inceptisols of Spain. Soil Science Society of America Journal, 53: 462-466. doi.10.2136/sssaj1989. 03615995005 300020026x.

Shukla, K., Kumar, B., Naaz, A., Narayan, C., 2016. Phosphorus fractions in irrigated and rainfed agricultural soils of Central India. Journal of the Indian Society of Soil Science, 64 (2): 148-156. doi.10.5958/0974-0228.2016.00019.0.
Tandon, H.L.S., 1987. Phosphorous research and agricultural production in India. Fertility Development and Consultant Organization, Food and Agriculture Organization of the United Nations, Greater Kailash 1, New Delhi.

Uygur, V., Karabatak, I., 2009. The effect of organic amendments on mineral phosphate fractions in calcareous soils. Journal of Plant Nutrition and Soil Science, $\quad$ 172(3): 336-345. doi.10.1002/jpln.200700326.

Uygur, V., Durgun, B., Şenol, H., 2017. Chemical fractions of phosphorus: the effect of soil orders, soil properties, and land use. Communications in Soil Science and Plant Analysis, 48: 1319-1335. doi.org/10.1080/00103624.2017.1341919.

Violante, A., Pigna, M., Ricciardella, M., Gianfreda, L., 2002. Adsorption of phosphate on variable charge minerals and soils as affected by organic and inorganic ligands. Development in Soil Science, 28A: 279-295.

Walker, T., Syers. J., 1976. The fate of phosphorus during pedogenesis. Geoderma, 15: 1-19. doi.org/10.1016/S0166-2481(02)80057-5.

Weaver, R. M. 1974. A simplified determination of reductant-soluble phosphate in soil phosphate fractionation schemes. Soil Science Society of American Proceedings, 38: 153-54.

Wei, S., Tan, W., Liu, F., Zhao, W., Weng. L., 2014. Surface properties and phosphate adsorption of binary systems containing goethite and kaolinite. Geoderma, 213: 478-484. doi.org/10.1016/j.geoderma.2013.09.001.

Yi-Chao, S.H.I., Ziadi, N., Messiga, A.J., Lalande, R., Zheng-Yi, H.U., 2015. Soil phosphorus fractions change in winter in a corn-soybean rotation with tillage and phosphorus fertilization. Soil Science Society of China, 25 (1): 1-11. doi.org/10.1016/S1002-0160(14)60071-0. 